\title{
Fresh Unstable Trochanteric Fracture in Elderly Patients: Mortality, Readmission and Reoperation After Primary Hemiarthroplasty
}

\section{Tzu-Chieh Lin}

China Medical University

\section{Pin-Wen Wang}

China Medical University

Chun-Teng Lin

China Medical University

\section{Yu-Jun Chang}

Changhua Christian Hospital

\section{Ying-Ju Lin}

China Medical University Hospital

\section{Wen-Miin Liang}

China Medical University

Jeff Lin ( $\square$ cflin.ntpu@gmail.com )

National Taiwan University

\section{Research Article}

Keywords: Unstable trochanteric fracture, Hemiarthroplasty, Mortality, Readmission, reoperation

Posted Date: February 19th, 2021

DOl: https://doi.org/10.21203/rs.3.rs-199113/v1

License: (9) (i) This work is licensed under a Creative Commons Attribution 4.0 International License. Read Full License 


\section{Abstract}

Objectives: Most unstable trochanteric fractures are treated with internal fixation often with high complication rates. Hemiarthroplasty is an alternative treatment to achieve early weight-bearing, early mobilization and acceptable functional outcomes. However, few have investigated the long-term outcomes after hemiarthroplasty for unstable trochanteric fracture. We investigated patients with fresh trochanteric fracture after primary hemiarthroplasty on their long-term outcomes, including mortality, readmission and reoperation.

Methods: We studied a total of 2,798 elderly adults who had received hemiarthroplasty for fresh unstable trochanteric fracture from 2000 to 2010, and followed them up until the end of 2012. Survival analysis and Cox model were used to characterize mortality. Competing risk analysis and Fine and Gray model were used to estimate the cumulative incidences of the first readmission and the first reoperation.

Results: The follow-up mortality rate for 1-year was 17.94\%; 2-year, 29.76\%; 5-year, 56.8\%; and 10-year, 83.38\%. The cumulative incidence of the first readmission was $16.4 \%$ for 1 -year and $22.44 \%$ for 3 -year. The cumulative incidence of the first reoperation was $13.87 \%$ for 1 -year, $18.11 \%$ for 2 -year, $25.79 \%$ for 5 -year, and $38.24 \%$ for 10 year. Male, older age, larger $\mathrm{CCl}$ and lower insured amount were all risk factors for the overall mortality. Older age and larger $\mathrm{CCl}$ were risk factors for the first readmission. Older age was a protective factor for reoperation, which is likely due to the competing death.

Conclusion: Results are consistent with hemiarthroplasty being a robust alternative treatment for unstable trochanteric fracture among a heterogeneous elderly population.

\section{Introduction}

The incidence of osteoporotic hip fracture is increasing along with the expanding elderly population. Its treatment could end with excess mortality, morbidity and socioeconomic burden [1-3]. Osteoporotic hip fractures include either cervical fracture or the trochanteric fracture of femur in about 1:1 ratio of incidence.The optimal choice of operation and implant for unstable trochanteric fracture remains debatable [4,5]. Most unstable intertrochanteric fractures are treated with internal fixation. However, internal fixation often leads to multiple surgical complications, like loss of fixation, lag screw cut-out, collapse, malunion and implant failure. All these result in reoperation or converting to arthroplasty $[6,7]$. Therefore, arthroplasty is considered as an alternative treatment for unstable trochanteric fracture to achieve early weight-bearing, early mobilization, rapid rehabilitation and acceptable functional outcomes [7-10]. Grau et al. reported that $3.3 \%$ of $2,117,815$ intertrochanteric fractures were treated by hemiarthroplasty and the use of hemiarthroplasty to treat trochanteric fracture has increased over the period from 1990 to 2007 [7].

Recently, a number of studies, typically enrolled limited samples, have reported the short-term outcomes after hemiarthroplasty to treat unstable trochanteric fractures [8-18]. Furthermore, few studies investigated the longterm outcomes [11, 15-17]. Here, we conducted a population-based retrospective cohort study on fresh intertrochanteric fracture investigating the mid-and long-term outcomes (like overall mortality, readmission and reoperation) after primary hemiarthroplasty. The method of competing risk analysis was used.

\section{Methods}




\section{Data Sources}

Data were retrospectively collected from two sources: the National Health Insurance Research Database (NHIRD) (details available at: http://nhird.nhri.org.tw/en/index.htm) and the National Register of Deaths Database (NRDD). These databases and another 70 health-related databases are real-world dataandmaintained by Taiwan's Ministry of Health and Welfare Health and Welfare (MOHW) Data Center. The completeness and accuracy of these two databases are $>98 \%$ and are endorsed by MOHW. Taiwan National Health Insurance (NHI) program was started in 1995, providing mandatory health insurance for $>99 \%$ of all the 23 million residents in Taiwan. The NHIRD contains individuals' e-claims of all NHI beneficiaries from 1996 to the present. Our study was approved by the Research Ethics Committee, China Medical University Hospital (certificate: CMUH-104-REC2115).

\section{Subjects}

Like our previous report [19], inclusion criteria were subjects aged 60 years or older with the following two conditions: (a) a first discharge diagnosis code of intertrochanteric hip fracture based on the International Classification of Diseases, 9th Revision, Clinical Modification (ICD-9-CM) codes 820.20, 820.21, 820.30 and 820.31 , and (b) a procedure code corresponding to surgery for hemiarthroplasty based on ICD9-CM codes 81.52 during the period from 1 January 2000 to 31 December 2010. The first admission date for trochanteric fracture was defined as the index date of surgery. The exclusion criteria were subjects with pathological fractures (ICD9CM codes 733.14 and 733.15) or open hip fractures (ICD9-CM codes 820.1, 820.10, 820.11, 820.12, 820.19, and 820.9). To avoid confounding effects, we excluded subjects undergoing gone surgery before the index date for injuries to the pelvis, femur, or hip region. We extracted a total 2,798 subjects receiving hemiarthroplasty for fresh trochanteric fracture. According to the guideline of the National Health Insurance (NHI) program in Taiwan, all the hemiarthroplasty operationsfor trochanteric fractureswere reviewed through a peer-review system within NIH program, by at least three board-certificated orthopedic surgeons and they approved the proposed operations. The end of the study was eitherthe date of death, the date of exiting from NHI program, or December 31, 2012, the last follow-up date.

\section{Outcomes of interest}

Three endpoints were studied: (a) overall cumulative mortality; (b) cumulative incidence of the first readmission due to medical complications within 6 months after the index surgery; (c) cumulative incidence of the first reoperation due to surgical complications. The overall survival time was calculated from the index date to the date of death. Subjects who survived by the end of study, the date of exiting from $\mathrm{NHI}$ program or the end of the study date (December 31, 2012) were defined as censored. The first readmission time was the time from the index date to the date of the first readmission due to medical complications that required hospital readmission, within 6 months after the index surgery. The 6-month medical complications included stroke, acute myocardial infarction, pulmonary embolism, acute renal failure, and acute respiratory failure. The first reoperation time was calculated from the index date to the date of the first postoperative unplanned reoperation due to surgical complications secondary to hemiarthroplasty. Reoperations for surgical complications were debridement of previous operative wound, conversion to total hip arthroplasty, revision of hemiarthroplasty, removal of implant or close/open reduction for dislocation.

\section{Statistical analysis}


Overall survival rates were estimated using the Kaplan-Meier method. We explored effects of risk factors on the overall survival using both the log-rank test and multiple variables Cox's proportional hazards model. Elderly adults in our study typically had a high mortality rate due to ageing and multiple comorbidities. A high competing risk of death could interfere with the estimation of cumulative incidences on the first readmission and the first reoperation. The Kaplan-Meier method overestimates the cumulative incidences of the first readmission and the first reoperation if not considering competing death. Therefore, we estimated these cumulative incidences using the competing risk analysis with death treated as a competing event. In addition, we also explored risk factors on the first readmission time and the first reoperation time using the Gray's test and the Fine and Gray's model. These methods are multivariate subdistribution hazard models based on competing risk analysis [20,21]. All data management and analyses were performed using the statistical package SAS 9.4 (SAS Institute, Cary, NC) and R libraries survival, cmprsk, and mstate, R 3.6.1 (available at http://www.R-project.org/, R Development Core Team (2019), R: A language and environment for statistical computing. (R Foundation for StatisticalComputing, Vienna, Austria).

\section{Results}

During 2000 to 2010 , a total of 76,798 subjects aged 60 years or older were admitted for the first time with a primary diagnosis of trochanteric fracture. Of these, 2,798 subjects were included in the study. They satisfied the inclusion/exclusion criteria and underwent hemiarthroplasty as the primary treatment for trochanteric fracture. As shown in Table 1, the cohort consisted of 1,903 (68.0\%) women and 895 (32\%) men. Their mean age was 79 years old. Females had slightly higher mean age, lower Charlson comorbidity index (CCl) score and higher insurance amount. 
Table 1

Baseline characteristics of patients receiving hemiarthroplasty for intertrochanteric hip fractures stratified by gender

\begin{tabular}{|c|c|c|c|c|c|c|c|c|}
\hline & \multicolumn{8}{|c|}{ Gender } \\
\hline & & \multicolumn{2}{|l|}{ Total } & \multicolumn{2}{|c|}{ Male } & \multicolumn{3}{|c|}{ Female } \\
\hline & & \multicolumn{2}{|c|}{$(n=2,798)$} & \multicolumn{2}{|c|}{$(n=895)$} & \multicolumn{2}{|c|}{$(n=1,903)$} & \\
\hline & & $\mathrm{N}$ & $\%$ & $\mathrm{~N}$ & $\%$ & $\mathrm{~N}$ & $\%$ & $P$-value \\
\hline \multirow[t]{7}{*}{ Age (yrs) } & Mean $\pm S D^{a}$ & \multicolumn{2}{|c|}{$79.75 \pm 7.86$} & \multicolumn{2}{|c|}{$78.74 \pm 7.78$} & \multicolumn{2}{|c|}{$80.23 \pm 7.85$} & $<0.001$ \\
\hline & $60-64$ & 113 & 4.04 & 48 & 5.36 & 65 & 3.42 & \\
\hline & $65-69$ & 226 & 8.08 & 82 & 9.16 & 144 & 7.57 & \\
\hline & $70-74$ & 407 & 14.55 & 139 & 15.53 & 268 & 14.08 & \\
\hline & $75-79$ & 599 & 21.41 & 209 & 23.35 & 390 & 20.33 & \\
\hline & $80-84$ & 737 & 26.34 & 236 & 26.37 & 501 & 26.33 & \\
\hline & $\geq 85$ & 716 & 25.59 & 181 & 20.22 & 535 & 28.11 & \\
\hline \multirow[t]{5}{*}{$\mathrm{CCI}^{\mathrm{b}}$ score } & 0 & 917 & 32.77 & 256 & 28.60 & 661 & 34.73 & $<0.001$ \\
\hline & 1 & 694 & 24.80 & 203 & 22.68 & 491 & 25.80 & \\
\hline & 2 & 372 & 13.30 & 137 & 15.31 & 235 & 12.35 & \\
\hline & 3 & 228 & 10.29 & 102 & 11.40 & 186 & 9.77 & \\
\hline & $\geq 4$ & 527 & 18.83 & 197 & 22.01 & 330 & 17.34 & \\
\hline \multirow[t]{2}{*}{ Insurance amount (NT\$) } & $\leq 21000$ & 1704 & 60.90 & 640 & 71.51 & 1064 & 55.91 & $<0.001$ \\
\hline & $>21000$ & 1094 & 30.10 & 255 & 28.49 & 839 & 44.09 & \\
\hline \multicolumn{9}{|c|}{ Note: ${ }^{a}$ SD: standard deviation. } \\
\hline
\end{tabular}

The1-month, 3-month, 6-month, 1-year, 2-year, 5-year and 10-year cumulative mortality rates were 3.15\%, 5.5\%, 7.4\%, 17.94\%, 29.76\%, 56.8\% and 83.38\%, respectively (Table 2). The 1-, 2-, 5-, and 10-years cumulative incidences of the first reoperation for surgical complications were $13.87 \%, 18.11 \%, 25.79 \%$ and $38.24 \%$, respectively (Table 2). The 1-, 3-, and 6-month cumulative incidences of the first readmission for medical complications were $16.4 \%, 22.44 \%$ and $27.13 \%$, respectively (Table 2 ). Females had lower cumulative mortalityafter 12-year follow-up (Table 2 and Fig. 1a). Females also had lower cumulative incidence of the first reoperation before 5-year follow-up; then, slightly higher cumulative incidences of the first reoperation after 8-year follow-up (Table 2 and Fig. 1b). Females had lower cumulative incidence of the first readmission (Table 2 and Fig. 1c). 
Table 2

Cumulative mortality rates and cumulative incidence of first reoperation or readmission after hemiarthroplasty for intertrochanteric hip fractures

\begin{tabular}{|c|c|c|c|c|c|c|c|c|c|}
\hline \multirow[b]{3}{*}{ Time } & \multicolumn{9}{|c|}{ Cumulative Incidence } \\
\hline & \multicolumn{3}{|c|}{ Cumulative mortality (\%) } & \multicolumn{3}{|c|}{ Reoperation (\%) } & \multicolumn{3}{|c|}{ Readmission (\%) } \\
\hline & Total & Male & Female & Total & Male & Female & Total & Male & Female \\
\hline 1-month & 3.15 & 3.24 & 3.10 & 6.55 & 8.43 & 5.67 & 16.40 & 16.98 & 16.13 \\
\hline 3-month & 5.50 & 6.48 & 5.04 & 10.06 & 12.77 & 8.79 & 22.44 & 24.58 & 21.65 \\
\hline 6-month & 7.40 & 8.83 & 6.73 & 11.93 & 14.38 & 10.83 & 27.13 & 31.06 & 25.28 \\
\hline 1-year & 17.94 & 22.23 & 15.92 & 13.87 & 16.38 & 12.81 & & & \\
\hline 2-year & 29.76 & 35.93 & 26.84 & 18.11 & 21.02 & 16.90 & & & \\
\hline 5-year & 56.80 & 63.11 & 53.78 & 25.79 & 27.69 & 25.20 & & & \\
\hline 10-year & 83.35 & 86.65 & 81.79 & 38.24 & 36.00 & 40.14 & & & \\
\hline
\end{tabular}

The statistically significant risk factors for the overall survival were male gender,older age, larger CCI score and lower insured amount (Table 3). For each 1-year increase in age, the hazard ratio (HR) increased by 1.056 (95\% $\mathrm{Cl}$ : 1.047-1.064). Males had death risks higherthan females, HR, 1.315 (95\% Cl: 1.166-1.482). Subjects with higher $\mathrm{CCl}$ scores had higher risks for death compared withthose with $\mathrm{CCl}$ score equal to 0 (CCI $=1, \mathrm{HR} 1.14,95 \%$ Cl: 1.12-1.55; CCI = 2, HR 1.69, 95\% Cl: 1.40-2.04; CCl = 3, HR 1.77, 95\% Cl: 1.45-2.16; CCl $\geq 4, \mathrm{HR} 2.43,95 \%$ Cl: 2.07-2.86, respectively). The significant risk factor for the first reoperation was only younger age. For each 1-year increase in age, the sub-distribution hazard ratio (sHR) decreased 1.4\% (sHR: 0.986, 95\% Cl: 0.974-0.998) (Table 3). Conversely, the significant risk factors for the first readmission were older age and higher $\mathrm{CCl}$ score. For each 1-year increase in age, the sub-distribution hazard ratio (sHR) increased by 1.024 (95\% Cl: 1.016-1.032) (Table 3). 
Table 3

(a) Hazard ratios of the risk factors associated with death from cause-specific hazard model based on multivariate Cox's model, (b) subdistribution hazard ratio of the risk factors associated with the first reoperation, and (c) first readmission based on multivariate Fine and Gray's (subdistribution hazard ratio, sHR) model from competing risk analysis

\begin{tabular}{|c|c|c|c|c|c|c|c|c|c|c|}
\hline & & \multicolumn{3}{|c|}{ (a) Death } & \multicolumn{3}{|c|}{ (b) Reoperation } & \multicolumn{3}{|c|}{ (c) Readmission } \\
\hline & & HR & 95\% C.I. & $\begin{array}{l}P \text { - } \\
\text { value }\end{array}$ & sHR & 95\% C.I. & $\begin{array}{l}P \text { - } \\
\text { value }\end{array}$ & sHR & 95\% C.I. & $\begin{array}{l}P \text { - } \\
\text { value }\end{array}$ \\
\hline $\begin{array}{l}\text { Age } \\
\text { (year) }\end{array}$ & & 1.056 & $\begin{array}{l}(1.047- \\
1.064)\end{array}$ & $\begin{array}{l}< \\
0.001\end{array}$ & 0.986 & $\begin{array}{l}(0.974- \\
0.998)\end{array}$ & 0.025 & 1.024 & $\begin{array}{l}(1.016- \\
1.032)\end{array}$ & $\begin{array}{l}< \\
0.001\end{array}$ \\
\hline \multirow[t]{2}{*}{ Gender } & Female & Ref. ${ }^{b}$ & & & Ref. & & & Ref. & & \\
\hline & Male & 1.315 & $\begin{array}{l}(1.166- \\
1.482)\end{array}$ & $\begin{array}{l}< \\
0.001\end{array}$ & 0.966 & $\begin{array}{l}(0.770- \\
1.213)\end{array}$ & 0.768 & 0.951 & $\begin{array}{l}(0.829- \\
1.090)\end{array}$ & 0.468 \\
\hline \multirow[t]{5}{*}{$\mathrm{CCl}^{\mathrm{a}}$} & 0 & Ref. & & & Ref. & & & Ref. & & \\
\hline & 1 & 1.139 & $\begin{array}{l}(1.123- \\
1.548)\end{array}$ & $\begin{array}{l}< \\
0.001\end{array}$ & 1.038 & $\begin{array}{l}(0.797- \\
1.351)\end{array}$ & 0.784 & 1.365 & $\begin{array}{l}(1.172- \\
1.590)\end{array}$ & $\begin{array}{l}< \\
0.001\end{array}$ \\
\hline & 2 & 1.693 & $\begin{array}{l}(1.404- \\
2.041)\end{array}$ & $\begin{array}{l}< \\
0.001\end{array}$ & 0.898 & $\begin{array}{l}(0.634- \\
1.270)\end{array}$ & 0.542 & 1.684 & $\begin{array}{l}(1.388- \\
2.044)\end{array}$ & $\begin{array}{l}< \\
0.001\end{array}$ \\
\hline & 3 & 1.766 & $\begin{array}{l}(1.445- \\
2.159)\end{array}$ & $\begin{array}{l}< \\
0.001\end{array}$ & 1.087 & $\begin{array}{l}(0.764- \\
1.547)\end{array}$ & 0.642 & 1.656 & $\begin{array}{l}(1.320- \\
2.077)\end{array}$ & $\begin{array}{l}< \\
0.001\end{array}$ \\
\hline & $\geq 4$ & 2.432 & $\begin{array}{l}(2.070- \\
2.856)\end{array}$ & $\begin{array}{l}< \\
0.001\end{array}$ & 0.886 & $\begin{array}{l}(0.648- \\
1.210)\end{array}$ & 0.447 & 2.103 & $\begin{array}{l}(1.752- \\
2.524)\end{array}$ & $\begin{array}{l}< \\
0.001\end{array}$ \\
\hline \multirow{2}{*}{$\begin{array}{l}\text { Insurance } \\
\text { amount } \\
\text { (NTS) }\end{array}$} & $\leq$ & Ref. & & & Ref. & & & Ref. & & \\
\hline & $\begin{array}{l}> \\
21000\end{array}$ & 0.487 & $\begin{array}{l}(0.425- \\
0.557)\end{array}$ & $\begin{array}{l}< \\
0.001\end{array}$ & 1.174 & $\begin{array}{l}(0.950- \\
1.450)\end{array}$ & 0.138 & 0.912 & $\begin{array}{l}(0.803- \\
1.036)\end{array}$ & 0.158 \\
\hline \multicolumn{11}{|c|}{ Note: ${ }^{a} \mathrm{CCl}$ : Charlson Comorbidity Index. } \\
\hline
\end{tabular}

Subjects surviving after index surgery typically had multiple reoperations and readmissions due to complications. A total 356 subjects had at least one reoperation within 10 years after index surgery. Causes for reoperation were dislocation (30.4\%), infection (40.73\%), periprosthetic fracture (20.5\%) and mechanical complications (41.2\%). Surgical complications resulted in 40 revisions, $1.4 \%$ among total 2,798 subjects after the index surgery. For patients receiving reoperation after index surgery, the cumulative mortality rates after the first reoperation within 1-month, 3-month, 6-month, 1-year, 2-year, 5-year follow-up were 4.5\%, 13.67\%, 19.45\%, 28.62\%, $39.25 \%$ and $61.95 \%$ respectively (Table 4). A total 759 subjects had at least one readmission within 6 months after the index surgery. Causes for readmission in descending order were urinary tract infection (60\%), pneumonia (37\%), acute respiratory failure (25\%), acute renal failure (10.9\%) and major cardiovascular events. Cumulative mortality rates after first medical readmission within 1, 3 and 6 months after the index surgery were $14.17 \%, 23.61 \%$ and $30.85 \%$ respectively (Table 4 ). 
Table 4

Causes of the first reoperation or readmission after hemiarthroplasty for intertrochanteric hip fracture

\begin{tabular}{|c|c|c|c|c|c|c|c|}
\hline & $\begin{array}{l}\text { 1- } \\
\text { month }\end{array}$ & $\begin{array}{l}\text { 3- } \\
\text { month }\end{array}$ & $\begin{array}{l}\text { 6- } \\
\text { month }\end{array}$ & $\begin{array}{l}\text { 1- } \\
\text { year }\end{array}$ & $\begin{array}{l}2- \\
\text { year }\end{array}$ & $\begin{array}{l}5- \\
\text { year }\end{array}$ & $\begin{array}{l}10- \\
\text { year }\end{array}$ \\
\hline \multicolumn{8}{|l|}{ Reoperation } \\
\hline $\mathrm{N}^{\mathrm{a}}$ & 127 & 199 & 228 & 250 & 283 & 330 & 356 \\
\hline Dislocation (\%b) & 36.22 & 41.71 & 40.97 & 40.00 & 36.04 & 31.82 & 30.34 \\
\hline Mechanical complications ${ }^{\complement}(\%)$ & 35.43 & 36.18 & 37.72 & 39.20 & 40.99 & 41.21 & 40.43 \\
\hline Infection (\%) & 34.65 & 35.18 & 39.04 & 39.60 & 36.58 & 41.21 & 40.73 \\
\hline Removal of implant (\%) & 14.17 & 13.07 & 14.91 & 16.00 & 18.37 & 20.30 & 20.79 \\
\hline $\begin{array}{l}\text { Conversion to / revision arthroplasty } \\
\text { (\%) }\end{array}$ & 4.72 & 6.03 & 6.14 & 7.60 & 10.60 & 11.82 & 11.80 \\
\hline Isilateral femur fracture (\%) & 14.17 & 15.08 & 14.47 & 14.80 & 17.67 & 19.09 & 20.51 \\
\hline \multicolumn{8}{|l|}{ Readmission } \\
\hline $\mathrm{N}$ & 459 & 628 & 759 & & & & \\
\hline Urinary tract infection (\%) & 55.34 & 58.28 & 60.87 & & & & \\
\hline Pneumonia (\%) & 28.54 & 33.28 & 37.42 & & & & \\
\hline Acute respiratory failure (\%) & 17.86 & 22.29 & 25.30 & & & & \\
\hline Stroke (\%) & 10.46 & 11.15 & 10.67 & & & & \\
\hline Acute renal failure (\%) & 8.50 & 11.31 & 10.94 & & & & \\
\hline Acute myocardial infarction (\%) & 4.14 & 4.62 & 4.48 & & & & \\
\hline Pulmonary embolism (\%) & 1.96 & 1.59 & 1.71 & & & & \\
\hline Deep vein thrombosis (\%) & 0.87 & 1.43 & 1.45 & & & & \\
\hline
\end{tabular}

\section{Discussion}

Our main findings are various mortality rates of the study population (1-month, 3-month, 6-month, 1-year, 2-year, 5-year and 10-year cumulative mortality rates were 3.15\%, 5.5\%, 7.4\%, 17.94\%, 29.76\%, 56.8\% and 83.38\%, respectively) (Table 2). Several other studies reported the short-term outcomes after hemiarthroplasty for unstable trochanteric fracture with various results [8-18]. Their sample sizes are rather small (from 29 to 277 ) and most $(>70 \%)$ of them had sample sizes $<100$ [8-10, 12-14, 18, 22-28]. Discrepancy in mortality rates among studies could bedue to differences in selection criteria, distributions of gender and age in the populations, pre-fracture physical activity, bone quality, nutrition, and comorbidities, in addition to sample sizes. Our onemonth mortality was $3.15 \%$ in Taiwan, lower than $4-13.8 \%$ of the previous reports $[9-12,14,28]$. One possible reason is the progressive improvement in general medical careand healthcare with time. Our cohort started from 2000 which is a time more recent than most of those in the literature. The similar cohort effects can also be 
found in the previous studies from Korean $[9,15,28]$. Our 3-month mortality was 5.5\%, lower than 7.0-26.6\% reported in the previous studies $[10,12,28]$. Our 6 -month mortality of $7.42 \%$, which is also lower than $23.5-26.4 \%$ reported in the literature $[10,22,27]$. Cornwall et al. investigated the short-term mortality rates of 4 types of hip fractures [29]. Their in-hospital and 6-month mortality rates were $0 \%$ and $5.7 \%$ for 70 nondisplaced femoral neck fractures, $2.2 \%$ and $15.8 \%$ for 181 displaced femoral neck fractures, $2.8 \%$ and $12.8 \%$ for 108 stable intertrochanteric fractures and $1.1 \%$ and $13.8 \%$ for 178 unstable intertrochanteric fractures [29]. However, our 1year mortality rate was $17.9 \%$ higher than $2.5-14.6 \%$ of the previous studies $[13,25,26]$, but still lower than $21.8-39.3 \%$ in most past studies [9-12, 14-18, 28]. Our 2-year mortality rate was $29.7 \%$, which falls in the midrange of $12.5-59.0 \%$, as reported in the literature $[8,9,12,16,25,28]$. One possible reason is the accessibility of the long-term healthcare services in Taiwan for theses fragile seniors and disables. Our long-term healthcare services were started first in 2017. Before that time, our long-term healthcare system/service was worse than those of the major developed countries or welfare states. Therefore, our mortality rates after 1-year follow-up jumped into the middle range of the previous reports. Our 5-year mortality rate was $56.8 \%$ which was slightly higher than 52-64\%, as reported in the literature for all hip fractures [2, 3, 19, 30]. Few studies reported 5-year mortality rates after hemiarthroplasty for unstable intertrochanteric fracture [16, 17]. Camurcu et al. and Cobden et al. reported their 5 -year mortality rates as high as $94.4 \%$ and $90.25 \%$, respectively $[16,17]$. One important reason for the large differences in mortality rates between studies of ours and others $[16,17]$ is related to their smaller sample sizes. For a study with a smaller sample size study containing high mortality elderly adults, only a few number of survival subjects were left toward the end of the study such that a small number of deaths would cause huge impact on the change of the mortality rate and cause a sharp rise for the mortality rate at the end of the study.

Our short-term mortality rates after hemiarthroplasty for unstable trochanteric fracture are not higher than those hemiarthroplasty reported for cervical fracture and internal fixation for trochanteric fracture. For example, Forte et al. found 1-, 2-, and 3-month mortality rates among 192,365 elderly after internal fixations for trochanteric fractures are $7.92 \%, 12.34 \%$ and $15.19 \%$, respectively [31]. The meta analyses of Mundi and Li et al. for the outcomes after trochanteric fracturesfound the 1-year mortality rate being $23 \%$ and $17 \%[32,33]$. Tucker et al. conducted a prospective including 3,230 unstable trochanteric fractures with internal fixations and found the 1year mortality rate being $22.6 \%$ [34]. Mattisson et al. reported a study for trochanteric fracture based on a database from Swedish fracture register and found that the overall 30-day and 1-year mortality rates being $7.7 \%$ and $26 \%$ [35]. In contrast, our 5-year and 10-year mortality rates after hemiarthroplasty for unstable trochanteric fracture were $56.8 \%$ and $83.3 \%$, which areall higher than those reported in the literature after hemiarthroplasty for cervical fracture $[2,3,19,30]$. Lin and Liang examined the outcomes of subjects after hemiarthroplasty for displaced cervical fracture. They reported the 5-and 10-year mortality rates being $46.9 \%$ and $71 \%$ [19]. Studies reported that subjects with trochanteric fractures tended to be older, in worse health conditions and higher shortterm mortality rates than those with femoral neck fractures $[27,36]$. We believe that unstable trochanteric fracture with sequelae and aging both of which impact on the high mortality one year after fractures.

Other main findings of our study are the significant risk factors for overall survival rate being male gender, older age, larger $\mathrm{CCl}$ score and lower insured amount. Few studies reported on the risk factors for hemiarthroplasty after unstable trochanteric fracture [17]. Camurcu et al. reported 106 subjects after cementer bipolar hemiarthroplasty for unstable trochanter fracture and found that risk factors for 1-year mortality being American Society of Anesthesiologists (ASA) scores $\geqq 3$, delayed postoperative mobilization $\geqq 2$ days and presence of $\geqq 3$ 
comorbidities. Camurcu et al. did not find age and male being risk factors for 1-year mortality. Several metaanalyses reported that older age, male gender and multiple preoperative comorbidities are significant risks for mortality and medical complications after hip fractures in the elderly $[1,37]$. We found that males had a hazard 1.31 times of females and age had hazard yearly 1.05 times higher for the overall mortality. We used $\mathrm{CCl}$ score representing the number and severity of comorbidities. Other investigators used instead ASA score for unstable trochanteric fractures $[11,12,14,16,23,24,28]$. Higher CCl, aging, higher ASA scores and delayed surgery are highly correlated with one another. Multiple comorbidities and aging often result in high ASA scores.We found that $\mathrm{CCl}$ score had stronger association with mortality than ASA score (data not shown here). CCI score or ASA score are in positive and strong correlation. They are bothgood measures for the number and severity of comorbidities. Since several studies had shown $\mathrm{CCl}$ score as a significantrisk factor associated with the mortality after hip fractures $[38,39]$. For this reason, we had chosen $\mathrm{CCl}$ score as the measure for the severity of multiple comorbidities.

Several other studies reported readmission rates and reoperation rates after hemiarthroplasty for unstable trochanteric fracture $[9-11,13-15,18,22,25,28]$. However these studies did not consider the interferences caused by the competing risk of deaths in estimating the cumulative incidence of the readmission and the reoperation rates. It is therefore difficult to compare their findings with ours. Other difficulties are the large variations in sample size across studies, the differences in the definition of causes for the readmissions, the follow-up times and the lost follow-up rates. We found that the 1-, 3-, and 6-month cumulative incidences of the first readmission after medical complications were $16.4 \%, 22.44 \%$ and $27.13 \%$, respectively, using competing risk analysis. Previous studies reported the 1- to 6-month rates of medical complications ranged from $11.2-41.8 \%$ for subjects after hemiarthroplasty for unstable trochanteric fracture [9-11, 13, 18, 22, 25]. Several other studies reported the one-month readmission rates due to medical complications from $5.3-17.1 \%$ for all types of hip fractures [40-42]. Our cumulative incidences of the first readmission due to medical complications after hemiarthroplasty for trochanteric fracture seemhigher than those cervical fracture reported in literature $[9-11,13$, $18,19,22,25,40]$. Subjects with trochanteric fracture are older than those with cervical fracture of femur. Therefore, the first readmission rates are often higher in trochanteric fracture. We found that older age and larger $\mathrm{CCl}$ score are risk factors for the first readmission. In the literature review of Ali and Gobbons, they summarized that age, preoperative comorbidities are strong independent predictors of readmission after hip fracture operations [43]. Male gender, unlike for mortality, was not found to be a risk factor for readmission in our study. Pollock et al. did not find male gender being a risk for readmission in 1,486 subjects after hip fracture operations [44]. Lizaur-Utrilla et al. found that female gender, higher ASA score and more than 2 comorbidities are risk factors for readmission among 732 subjects after hip fractures [45]. And French et al. also found that female gender and multiple comorbidities are risk factors for readmission in 41,331 subjects after hip fractures [46]. That females have similar or higher risk for readmission might be due to the lower competing risk of death.Although Ali and Gibbons also found that ASA score being a predictor of readmission more robust than the $\mathrm{CCl}$ score or individual comorbidities [43]. However, we found the association with readmission was stronger with $\mathrm{CCl}$ score than with ASA score.

We found that 1-, 2-, 5-, and 10-years cumulative incidences of the first reoperation were $13.87 \%, 18.11 \%, 25.79 \%$, and $38.24 \%$, respectively. In the literature, large disparities existregarding surgical complications or reoperation rates after hemiarthroplasty for unstable trochanteric fractures $[9-11,13-15,18,22,25,28]$. The 6 -month surgical complication/reoperation rates arearound 2.2\% [22]; one-year surgical complication/reoperation rates 
are from 2.6-20\% $[10,13,14]$ and 2-year surgical complication/reoperation rate are from 2.4-18.3\% $[9,18,25$, 28]. Surgical site infection, dislocation and periprosthetic fracture are three major causes of the reoperations [9$11,13-15,18,22,25,28]$. The 1 -year reoperation rates are from $2.9-16.3 \%$ after hemiarthroplasty for displaced femoral neck fracture in the literature $[19,47,48]$. By contrast, in our study, older age was a protective factor for reoperation. For each yearly increase in age, the sub-distribution hazard ratio (sHR) dropped by $1.4 \%$ (sHR: 0.986 , 95\% Cl: 0.974-0.998) for reoperation. Again, the different directions of the risks between the long-term mortality and the reoperation were due to the competing risk of death. Therefore, the more healthy subjects would be left in the risk set for reoperation, resulting in lowering the risk for reoperation. The competing risk of death usually has a larger impact on the outcomes of long-term than of short-term. We did not identify other significant risk factors for reoperation apart from younger age. Competing risk of death partly explains for that.The reoperation rates of hemiarthroplasty for unstable trochanteric fractureare still comparable to hemiarthroplasty after femoral neck fracture. Therefore, we speculate that hemiarthroplasty is likely a robust alternative management for unstable trochanteric fracture among a heterogeneous elderly population.

Our retrospective population study has several limitations. The database, unlike hip fracture registry database or prospective study, does not contain all clinical parameters. Retrospective studies often are vulnerable to selection bias and unknown confounding factors. All the hemiarthroplasty operations were required to be approved in advance by 3 orthopedic surgeons through peer-review system of NIH program such that it could reduce large selection bias. However, no pre-approval was required for internal fixation. And no standard criteria or nor guidance existed for the diagnosis and implant selection of unstable trochanteric fracture for internal fixation. Therefore, we did not include internal fixation for trochanteric fracture as controls to avoid large selection bias. Subjects were enrolled from 2000 to 2010 and followed up from 2- to 10-year in the study. During the long study period and the long follow-up time, regular healthcare improvements take place in admission policy and postoperative period required. Therefore, some confounding factors or lurking factors were not completely controlled usingstatistical modeling approaches. The ICD codes for medical complications and surgical complications always had variations such that misclassifications existed to interfere in estimating the readmission rates and reoperation rates. The distinctions between medical complications and newly developed comorbidities were not well separated after a major surgery. We therefore interpreted a shorter time duration (from the index date to the date of the first medical readmission) reflecting a higher probability index surgery leading directly or indirectly to readmissions related to medical complications. Furthermore, extrapolations from the readmission rate and reoperation rate should be done with caution.

\section{Conclusions}

This is the first study to assess the long-term effects of fresh unstable trochanteric fracturestreated with hemiarthroplasty. Male gender, older age and larger $\mathrm{CCl}$ score and lower insured amount were risk factors for the overall mortality. Older age and larger $\mathrm{CCl}$ score were risk factors for the first readmission. Conversely, we found that older age was a protective factor for reoperation, which is likely due to the competing death. Compared with previous studies, with respect to surgical complications, we speculate that hemiarthroplasty is a robust alternative treatment for unstable trochanteric fracture among a heterogeneous elderly population. More prospective studies and clinical trials are required in the future for the long-term outcomes after primary hemiarthroplasty for fresh unstable trochanteric fractures. 


\section{Abbreviations}

NHIRD

National Health Insurance Research Database; NRDD:National Register of Deaths Database; MOHW:Ministry of Health and Welfare Health and Welfare; NHI:National Health Insurance; ICD-9-CM:International Classification of Diseases, 9th Revision, Clinical Modification; CCl:Charlson comorbidity index; HR:Hazard ratio; Cl:Confidence interval; sHR:sub-distribution hazard ratio; ASA:American Society of Anesthesiologists.

\section{Declarations}

Acknowledgments

This study was based in part on data from the National Health Insurance Research Database provided by the Bureau of National Health Insurance, Department of Health and managed by the National Health Research Institutes. The interpretation and conclusions contained herein do not represent those of the National Health Insurance Administration, Department of Health, or National Health Research Institutes. We are grateful to Health Data Science Center, China Medical University Hospital, for providing administrative, technical, and funding support.

\section{Author Contributions}

All authors made substantial contributions to this work. TCL, WML, and JCFL designed the study; PWW and CTL facilitated acquisition of data; PWW, CTL and YJC performed the data analysis; TCL, WML, PWW, CTL, YJC, YJL, and JCFL interpreted the data; TCL, WML, and JCFL drafted the manuscript; and all authors critically revised the manuscript and approved the final version for submission.

\section{Funding}

This study was supported by funding from the China Medical University (CMU108-MF-32, CMU108-S-15, and CMU108-S-17), China Medical University Hospital (DMR-109-188 and DMR-109-192) and Ministry of Science and Technology, Taiwan (Grant no. 109-2410-H-039-002).

\section{Availability of data and materials}

The website of the Taiwan National Health Insurance Research Database is found at http://www.mohw.gov.tw/.

\section{Ethics and consent to participate}

The NHIRD is composed of anonymous secondary data released to the public for research purposes. All patients' data were encrypted using the same encryption algorithm to cross-link the data while protecting the privacy of the patients. This retrospective study was exempted from a full review by the local ethics review committee, but the protocol was approved by the Institutional Review Board (IRB) of China Medical University Hospital with a waiver of informed consent (certificate: CMUH-104-REC2-115). All methods were performed in accordance with the relevant guidelines and regulations.

\section{Consent for publication}


Not applicable.

\section{Competing interests}

The authors declare that they have no competing interests.

\section{References}

1. Abrahamsen B, van Staa T, Ariely R, Olson M, Cooper C. Excess mortality following hip fracture: a systematic epidemiological review. Osteoporos Int. 2009;20(10):1633-50.

2. Tsuboi M, Hasegawa $Y$, Suzuki S, Wingstrand $H$, Thorngren KG. Mortality and mobility after hip fracture in Japan: a ten-year follow-up. J Bone Joint Surg Br. 2007;89(4):461-6.

3. Wang CB, Lin CF, Liang WM, Cheng CF, Chang YJ, Wu HC et al. Excess mortality after hip fracture among the elderly in Taiwan: a nationwide population-based cohort study. Bone. 2013;56(1):147-53.

4. Kaplan K, Miyamoto R, Levine BR, Egol KA, Zuckerman JD. Surgical management of hip fractures: an evidence-based review of the literature. II: intertrochanteric fractures. J Am Acad Orthop Surg. 2008;16(11):665-73.

5. Quinn RH, Mooar PA, Murray JN, Pezold R, Sevarino KS. Treatment of Hip Fractures in the Elderly. J Am Acad Orthop Surg. 2017;25(5):e102-e4.

6. Ahrengart L, Törnkvist H, Fornander P, Thorngren KG, Pasanen L, Wahlström P et al. A randomized study of the compression hip screw and Gamma nail in 426 fractures. Clin Orthop Relat Res. 2002(401):209-22.

7. Grau L, Summers S, Massel DH, Rosas S, Ong A, Hernandez VH. Operative Trends in the Treatment of Hip Fractures and the Role of Arthroplasty. Geriatr Orthop Surg Rehabil. 2018;9:2151459318760634.

8. Rodop O, Kiral A, Kaplan H, Akmaz I. Primary bipolar hemiprosthesis for unstable intertrochanteric fractures. Int Orthop. 2002;26(4):233-7.

9. Kim SY, Kim YG, Hwang JK. Cementless calcar-replacement hemiarthroplasty compared with intramedullary fixation of unstable intertrochanteric fractures. A prospective, randomized study. J Bone Joint Surg Am. 2005;87(10):2186-92.

10. Chan KC, Gill GS. Cemented hemiarthroplasties for elderly patients with intertrochanteric fractures. Clin Orthop Relat Res. 2000(371):206-15.

11. Tang P, Hu F, Shen J, Zhang L, Zhang L. Proximal femoral nail antirotation versus hemiarthroplasty: a study for the treatment of intertrochanteric fractures. Injury. 2012;43(6):876-81.

12. Cankaya D, Ozkurt B, Tabak AY. Cemented calcar replacement versus cementless hemiarthroplasty for unstable intertrochanteric femur fractures in the elderly. Ulus Travma Acil Cerrahi Derg. 2013;19(6):548-53.

13. Görmeli G, Korkmaz MF, Görmeli CA, Adanaş C, Karataş T, Şimşek SA. Comparison of femur intertrochanteric fracture fixation with hemiarthroplasty and proximal femoral nail systems. Ulus Travma Acil Cerrahi Derg. 2015;21(6):503-8.

14. Esen E, Dur H, Ataoğlu MB, Ayanoğlu T, Turanlı S. Evaluation of proximal femoral nail-antirotation and cemented, bipolar hemiarthroplasty with calcar replacement in treatment of intertrochanteric femoral fractures in terms of mortality and morbidity ratios. Eklem Hastalik Cerrahisi. 2017;28(1):35-40. 
15. Kim JT, Kim HH, Kim JH, Kwak YH, Chang EC, Ha YC. Mid-Term Survivals After Cementless Bipolar Hemiarthroplasty for Unstable Intertrochanteric Fractures in Elderly Patients. J Arthroplasty. 2018;33(3):77782.

16. Cobden A, Camurcu Y, Duman S, Kocabiyik A, Kıs M, Saklavcı N. Mid-term survivals of cemented calcarreplacement bipolar hemiarthroplasty for unstable intertrochanteric fractures in elderly patients. Injury. 2019;50(12):2277-81.

17. Camurcu Y, Cobden A, Sofu H, Saklavci N, Kis M. What Are the Determinants of Mortality After Cemented Bipolar Hemiarthroplasty for Unstable Intertrochanteric Fractures in Elderly Patients? J Arthroplasty. 2017;32(10):3038-43.

18. Mansukhani SA, Tuteja SV, Kasodekar VB, Mukhi SR. A Comparative study of the Dynamic Hip Screw, the Cemented Bipolar Hemiarthroplasty and the Proximal Femoral Nail for the Treatment of Unstable Intertrochanteric Fractures. J Clin Diagn Res. 2017;11(4):RC14-RC9.

19. Lin JC, Liang WM. Outcomes after fixation for undisplaced femoral neck fracture compared to hemiarthroplasty for displaced femoral neck fracture among the elderly. BMC Musculoskelet Disord. 2015;16:199.

20. Beyersmann J, Allignol A, Schumacher M: Competing Risks and Multistate Models with R. New York, NY: Springer; 2012.

21. Ranstam J, Kärrholm J, Pulkkinen P, Mäkelä K, Espehaug B, Pedersen AB et al. Statistical analysis of arthroplasty data. II. Guidelines. Acta Orthop. 2011;82(3):258-67.

22. Bonnevialle P, Saragaglia D, Ehlinger M, Tonetti J, Maisse N, Adam P et al. Trochanteric locking nail versus arthroplasty in unstable intertrochanteric fracture in patients aged over 75 years. Orthop Traumatol Surg Res. 2011;97(6 Suppl):S95-100.

23. Desteli EE, İmren Y, Erdoğan M, Aydagün Ö. Quality of Life Following Treatment of Trochanteric Fractures with Proximal Femoral Nail versus Cementless Bipolar Hemiarthroplasty in Elderly. Clin Invest Med. 2015;38(2):E63-72.

24. Park BJ, Cho HM, Min WB. A Comparison of Internal Fixation and Bipolar Hemiarthroplasty for the Treatment of Reverse Oblique Intertrochanteric Femoral Fractures in Elderly Patients. Hip Pelvis. 2015;27(3):152-63.

25. Lee YK, Ha YC, Chang BK, Kim KC, Kim TY, Koo KH. Cementless bipolar hemiarthroplasty using a hydroxyapatite-coated long stem for osteoporotic unstable intertrochanteric fractures. J Arthroplasty. 2011;26(4):626-32.

26. Xie Y, Zhou H. Primary cemented hemiarthroplasty for unstable intertrochanteric fractures in elderly severe osteoporotic patients. Injury. 2020;51(3):670-3.

27. Fox KM, Magaziner J, Hebel JR, Kenzora JE, Kashner TM. Intertrochanteric versus femoral neck hip fractures: differential characteristics, treatment, and sequelae. J Gerontol A Biol Sci Med Sci. 1999;54(12):M635-40.

28. Kim JW, Shon HC, Song SH, Lee YK, Koo KH, Ha YC. Reoperation rate, mortality and ambulatory ability after internal fixation versus hemiarthroplasty for unstable intertrochanteric fractures in elderly patients: a study on Korean Hip Fracture Registry. Arch Orthop Trauma Surg. 2020.

29. Cornwall R, Gilbert MS, Koval KJ, Strauss E, Siu AL. Functional outcomes and mortality vary among different types of hip fractures: a function of patient characteristics. Clin Orthop Relat Res. 2004(425):64-71. 
30. von Friesendorff M, Besjakov J, Akesson K. Long-term survival and fracture risk after hip fracture: a 22-year follow-up in women. J Bone Miner Res. 2008;23(11):1832-41.

31. Forte ML, Virnig BA, Swiontkowski MF, Bhandari M, Feldman R, Eberly LE et al. Ninety-day mortality after intertrochanteric hip fracture: does provider volume matter? J Bone Joint Surg Am. 2010;92(4):799-806.

32. Mundi S, Pindiprolu B, Simunovic N, Bhandari M. Similar mortality rates in hip fracture patients over the past 31 years. Acta Orthop. 2014;85(1):54-9.

33. Li AB, Zhang WJ, Wang J, Guo WJ, Wang XH, Zhao YM. Intramedullary and extramedullary fixations for the treatment of unstable femoral intertrochanteric fractures: a meta-analysis of prospective randomized controlled trials. Int Orthop. 2017;41(2):403-13.

34. Tucker A, Donnelly KJ, Rowan C, McDonald S, Foster AP. Is the Best Plate a Nail? A Review of 3230 Unstable Intertrochanteric Fractures of the Proximal Femur. J Orthop Trauma. 2018;32(2):53-60.

35. Mattisson L, Bojan A, Enocson A. Epidemiology, treatment and mortality of trochanteric and subtrochanteric hip fractures: data from the Swedish fracture register. BMC Musculoskelet Disord. 2018;19(1):369.

36. Frisch NB, Wessell N, Charters M, Greenstein A, Shaw J, Peterson E et al. Hip Fracture Mortality: Differences Between Intertrochanteric and Femoral Neck Fractures. J Surg Orthop Adv. 2018;27(1):64-71.

37. Haentjens P, Magaziner J, Colón-Emeric CS, Vanderschueren D, Milisen K, Velkeniers B et al. Meta-analysis: excess mortality after hip fracture among older women and men. Ann Intern Med. 2010;152(6):380-90.

38. Radley DC, Gottlieb DJ, Fisher ES, Tosteson AN. Comorbidity risk-adjustment strategies are comparable among persons with hip fracture. J Clin Epidemiol. 2008;61(6):580-7.

39. Kirkland LL, Kashiwagi DT, Burton MC, Cha S, Varkey P. The Charlson Comorbidity Index Score as a predictor of 30-day mortality after hip fracture surgery. Am J Med Qual. 2011;26(6):461-7.

40. Cram P, Lix LM, Bohm E, Yan L, Roos L, Matelski J et al. Hip fracture care in Manitoba, Canada and New York State, United States: an analysis of administrative data. CMAJ Open. 2019;7(1):E55-E62.

41. Kristensen MT, Öztürk B, Röck ND, Ingeman A, Palm H, Pedersen AB. Regaining pre-fracture basic mobility status after hip fracture and association with post-discharge mortality and readmission-a nationwide register study in Denmark. Age Ageing. 2019;48(2):278-84.

42. BohI DD, Basques BA, Golinvaux NS, Miller CP, Baumgaertner MR, Grauer JN. Extramedullary compared with intramedullary implants for intertrochanteric hip fractures: thirty-day outcomes of 4432 procedures from the ACS NSQIP database. J Bone Joint Surg Am. 2014;96(22):1871-7.

43. Ali AM, Gibbons CE. Predictors of 30-day hospital readmission after hip fracture: a systematic review. Injury. 2017;48(2):243-52.

44. Pollock FH, Bethea A, Samanta D, Modak A, Maurer JP, Chumbe JT. Readmission within 30 days of discharge after hip fracture care. Orthopedics. 2015;38(1):e7-13.

45. Lizaur-Utrilla A, Gonzalez-Navarro B, Vizcaya-Moreno MF, Miralles Muñoz FA, Gonzalez-Parreño S, LopezPrats FA. Reasons for delaying surgery following hip fractures and its impact on one year mortality. Int Orthop. 2019;43(2):441-8.

46. French DD, Bass E, Bradham DD, Campbell RR, Rubenstein LZ. Rehospitalization after hip fracture: predictors and prognosis from a national veterans study. J Am Geriatr Soc. 2008;56(4):705-10.

47. Gao H, Liu Z, Xing D, Gong M. Which is the best alternative for displaced femoral neck fractures in the elderly?: A meta-analysis. Clin Orthop Relat Res. 2012;470(6):1782-91. 
48. Bhandari M, Einhorn TA, Guyatt G, Schemitsch EH, Zura RD, Sprague S et al. Total Hip Arthroplasty or Hemiarthroplasty for Hip Fracture. N Engl J Med. 2019;381(23):2199-208.

\section{Figures}

(a)

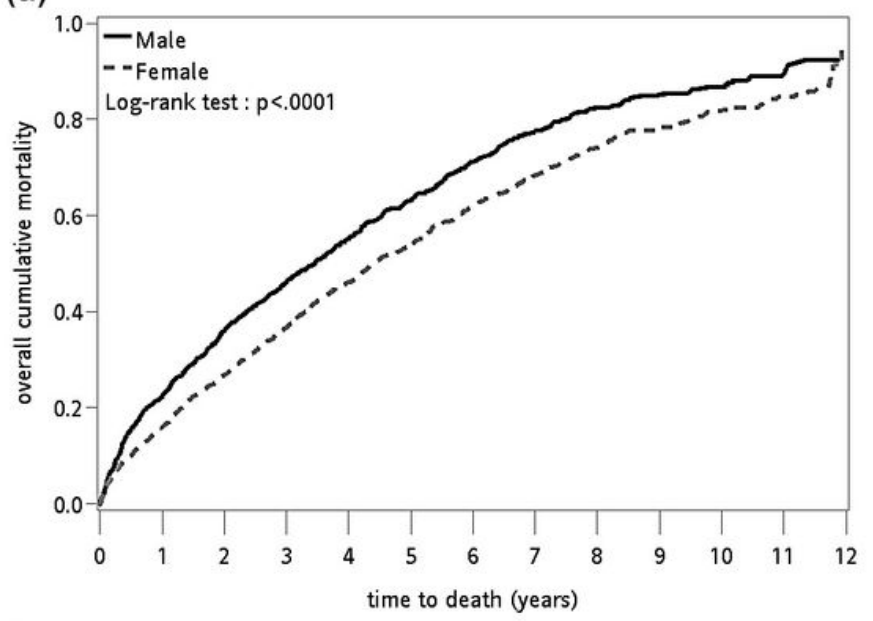

(b)

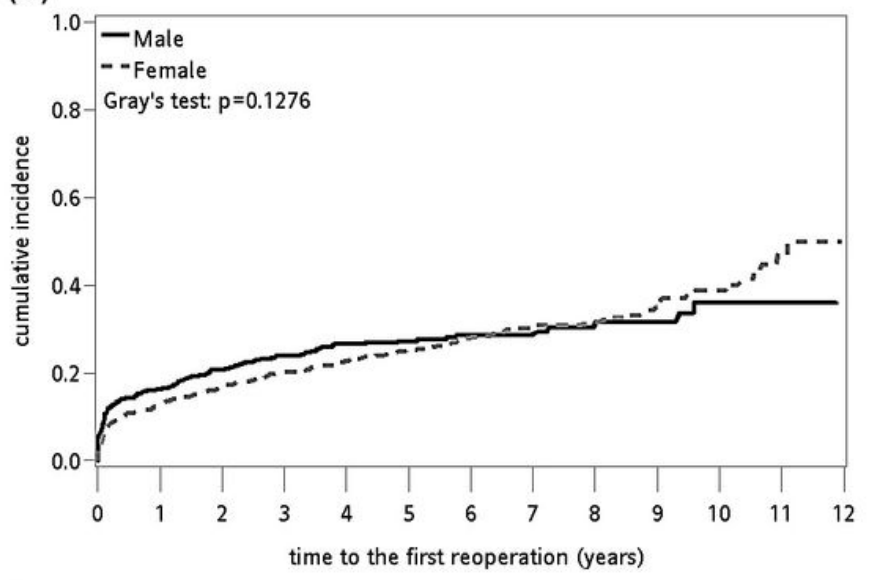

(c)

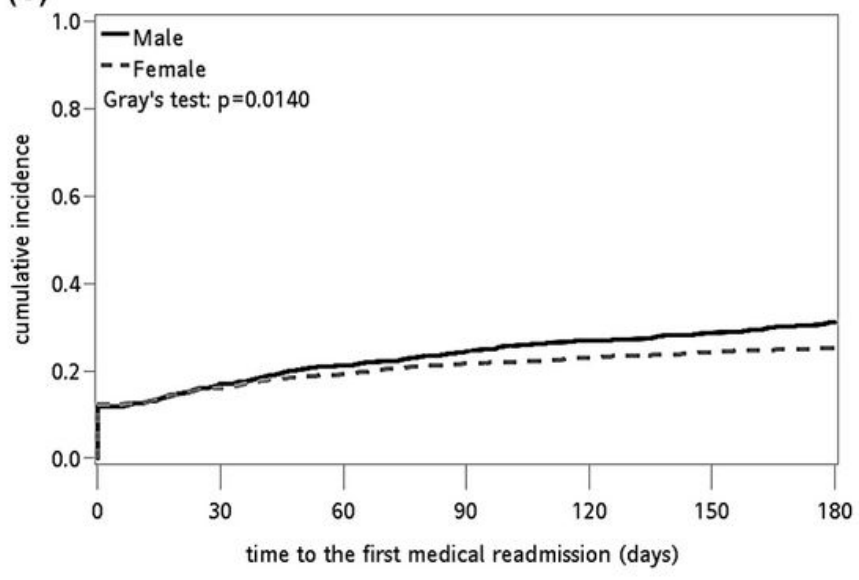

Figure 1

Twelve-year cumulative incidence curves of (a) mortality stratified by gender, (b) the first reoperation stratified by gender, and (c) 180-day cumulative incidence curves of the first readmission stratified by gender. 